\title{
BMJ Open Nurse staffing and patient-perceived quality of nursing care: a cross-sectional analysis of survey and administrative data in German hospitals
}

\author{
Vera Winter (1) , ${ }^{1,2}$ Karina Dietermann, ${ }^{2}$ Udo Schneider, ${ }^{3}$ Jonas Schreyögg ${ }^{2}$
}

To cite: Winter V, Dietermann $\mathrm{K}$, Schneider U, et al. Nurse staffing and patient-perceived quality of nursing care: a crosssectional analysis of survey and administrative data in German hospitals. BMJ Open 2021;11:e051133. doi:10.1136/ bmjopen-2021-051133

- Prepublication history and additional supplemental material for this paper are available online. To view these files, please visit the journal online (http://dx.doi.org/10.1136/ bmjopen-2021-051133).

Received 11 March 2021 Accepted 20 October 2021

A) Check for updates

(C) Author(s) (or their employer(s)) 2021. Re-use permitted under CC BY-NC. No commercial re-use. See rights and permissions. Published by BMJ.

${ }^{1}$ Schumpeter School of Business and Economics, University of Wuppertal, Wuppertal, Germany ${ }^{2}$ Hamburg Center for Health Economics, University of Hamburg, Hamburg, Germany

${ }^{3}$ Techniker Krankenkasse, Hamburg, Germany

Correspondence to

Dr Vera Winter;

winter@wiwi.uni-wuppertal.de

\section{ABSTRACT}

Objective To examine the impact of nurse staffing on patient-perceived quality of nursing care. We differentiate nurse staffing levels and nursing skill mix as two facets of nurse staffing and use a multidimensional instrument for patient-perceived quality of nursing care. We investigate non-linear and interaction effects.

Setting The study setting was 3458 hospital units in 1017 hospitals in Germany.

Participants We contacted 212554 patients discharged from non-paediatric, non-intensive and non-psychiatric hospital units who stayed at least two nights in the hospital between January and October 2019. Of those, 30174 responded, yielding a response rate of $14.2 \%$. Our sample included only those patients. After excluding extreme values for our nurse staffing variables and removing observations with missing values, our final sample comprised 28136 patients ranging from 18 to 97 years of age (average: 61.12 years) who had been discharged from 3458 distinct hospital units in 1017 hospitals.

Primary and secondary outcome measures Patientperceived quality of nursing care (general nursing care, guidance provided by nurses, and patient loyalty to the hospital).

Results For all three dimensions of patient-perceived quality of nursing care, we found that they significantly decreased as (1) nurse staffing levels decreased (with decreasing marginal effects) and (2) the proportion of assistant nurses in a hospital unit increased. The association between nurse staffing levels and quality of nursing care was more pronounced among patients who were less clinically complex, were admitted to smaller hospitals or were admitted to medical units.

Conclusions Our results indicate that, in addition to nurse staffing levels, nursing skill mix is crucial for providing the best possible quality of nursing care from the patient perspective and both should be considered when designing policies such as minimum staffing regulations to improve the quality of nursing care in hospitals.

\section{INTRODUCTION AND BACKGROUND}

Nurses are responsible for delivering the highest proportion of care to patients in hospitals and therefore a main contributor to quality of hospital care. Nurses who work on units with inadequate staffing are probably
Strengths and limitations of this study

- This study combines administrative data on hospital unit level nurse staffing with a multidimensional survey instrument that covers three aspects of patientperceived quality of nursing care in a sample of 28136 patients discharged from 3458 hospital units in Germany in 2019.

- This study demonstrates that the effect of nurse staffing on patient-perceived quality of care is nonlinear and depending on patient and hospital characteristics (patient case severity, hospital size, and medical vs surgical patients).

- Besides patient-to-nurse ratios, the study also adds insight on the effect of skill mix and patientto-physician ratios on patient-perceived quality of nursing care.

- The study is cross-sectional and cannot account for all potential endogeneity problems/even though considering the hospital unit type level is advantageous to using hospital-level aggregated data, omitted variables on hospital unit and patient level might remain.

not working as effective and efficient as nurses on better-staffed and better-skilled units. As a result, nurses do not have enough time for providing care and instructions, observe vital signs timely, and to respond to patients' individual needs., which leads to missed care and ultimately unfavourable clinical patient outcomes and bad patient experiences and perceptions of quality of care. A large body of empirical studies, including several literature reviews and meta-analyses, has examined how nurse staffing levels affect patient outcomes. ${ }^{1-10}$ Most studies have thereby relied on clinical outcomes available in administrative data and, for example, found significant effects of nurse staffing on mortality, pressure ulcers, and pneumonia. ${ }^{3}$ Several studies depict that the effect of inadequate nurse staffing on adverse events is through missed care. ${ }^{1-13}$ In light of calls for care 
(and, indeed, research) to be more patient oriented and for health systems to become more responsive to patient needs and expectations, ${ }^{14-16}$ the number of studies examining links between nurse staffing patterns and patient experiences of care-that is, perceived quality of carehas steadily grown. ${ }^{15-17}$ In addition, in the wake of many studies on the effects of skill mix on clinical outcomes, ${ }^{3}$ recent studies investigated the association between skill mix and patient-perceived quality of care..$^{15} 1819$

Several empirical studies that have analysed the relationship between nurse staffing levels and perceived quality of care have considered the nurse's rather than the patient's perspective. ${ }^{19-22}$ While the former is of course crucial, there is evidence that nurses' perceptions of the quality of their work can deviate substantially from the patients' perceptions. ${ }^{23}$ In addition, most studies that have analysed quality of care as an outcome have used measures that are very general (eg, single items to rate overall quality of care or patient safety). ${ }^{17222425}$ Outcome measures like these are less informative about the quality of care provided by nurses and therefore potentially less sensitive to nurse staffing. Some studies have used multidimensional constructs of patient satisfaction or patient experience with care. Yet, these constructs usually comprise dimensions and indicators that do not relate to nursing care, but other aspects, such as responsiveness of hospital staff, discharge information, and overall hospital rating, all of which are also indicators of other health professionals' quality of care. ${ }^{11} 162026$ Only a handful of studies have used items that ask directly about the quality of care provided by nurses, or quality of nursing care. ${ }^{20-22}$ To our knowledge, no studies to date have used a validated, multiitem, and multidimensional scale for patientperceived quality of nursing care.

Methodologically, examining the link between nurse staffing and patient outcomes is at risk of endogeneity problems, such as omitted variable bias (eg, skill mix, hospital-unit-type and patient characteristics, or physician staffing could all be related to nurse staffing and patient outcomes) or endogenous sorting (whereby hospitals devote more resources to patients with a higher risk of adverse outcomes). ${ }^{1481627}$ The risk of endogeneity increases with the level of aggregation; as many studies use staffing information at the aggregated hospital level, ${ }^{6} 1720212829$ they do not consider important information at the level of hospital units ${ }^{7031}$ or of patients. ${ }^{1632}$ At the other extreme, using microlevel data on the patient level $^{32}{ }^{33}$ usually implies substantial primary data collection efforts and a focus on one or few organisations, hence limiting generalisability. As an in-between approach, the number of studies using data at the level of hospital units has grown, ${ }^{7} 31$ 34-39 yet often suffers from limited sample sizes both in terms of patients and hospitals. ${ }^{15}$ In addition, recent evidence hints to the fact the effect of nurse staffing on quality of nursing care non-linear, that is, the effect of an additional nurse per patient might be high if nurse staffing is low; with higher numbers of nurses, the effect of each additional nurse probably decreases. ${ }^{15}$
Furthermore, recent studies indicate that the association between nurse staffing and patient outcomes can differ depending on patients' case severity, ${ }^{80}$ hospital size, ${ }^{641}$ and between medical versus surgical units. ${ }^{8}{ }^{28}$ Yet most of these studies have analysed the associations between nurse staffing and clinical patient outcomes.

The present study aims to shed further light on the association between nurse staffing and patient-perceived quality of nursing care. In particular, we examine this relationship between nurse staffing levels, nurse skill mix and patient-perceived quality of nursing care based on large-scale survey data combined with administrative data. Especially the use of a multidimensional survey instrument reflecting the patient perspective on nursing quality for measuring this relationship is quite novel. Second, we addressed substantial parts of potential endogeneity by including a rich set of patient-related and hospital-related control variables. Thereby, we specifically consider physician staffing and investigate to which degree physician staffing is a relevant predictor of patient-perceived quality of nursing care. In addition, we apply a fixed effects model to account for differences across hospital unit types, which seems important to reduce endogeneity problems. Finally, we allow for non-linear effects of nurse staffing on quality of nursing care and conduct subgroup analyses on patient case severity, hospital size, and medical versus surgical hospital units.

\section{METHODS}

\section{Data and sample}

This study is part of a larger project on the association between nurse staffing and quality of care. ${ }^{324}$ Our study analysed data from an online patient survey. To ensure the quality of the survey, we followed the scientific standards for scale development. The entire development and validation of the survey is described elsewhere. ${ }^{43}$ To sum up our proceeding, we drew on a systematic literature search and expert interviews to derive our initial items. We conducted two pretests (one paper and pencil pretest and one online pretest) with different participants and collected, discussed and reported all changes made to the survey. After data collection, we performed comprehensive exploratory and confirmatory factor analyses to ensure the validity and reliability of the survey. We combined the survey data with (1) claims data provided by the largest statutory health insurance fund in Germany and (2) data from the mandatory quality reports published annually by each hospital in the country. The combined data set comprised data from patients discharged from non-paediatric, non-intensive and non-psychiatric hospital units between January and October 2019. We define a hospital unit as an operating unit within a hospital that focuses on specific types of patients (eg, geriatrics or cardiology). Our sample included only those patients who stayed at least two nights in the hospital. We contacted patients in monthly waves and asked them to participate in the survey, 8 weeks 
after they had been discharged from the hospital at the latest. The survey contained questions related to patients' perceptions of the quality of the nursing care provided during their hospital stay. Each patient was contacted only once. In total, we contacted 212554 patients, of whom 30174 responded, yielding a response rate of $14.2 \%$. The response rate is comparable to other large-scale patient surveys. We checked for representativeness of the study population. Compared with the general population of hospitalised patients in Germany, our sample is generally representative in observable characteristics. Only the share of patients older than 80 is lower in our sample compared with the general population of hospitalised patients in Germany. We also compared respondents to non-respondents and did not find any substantial deviations in observable characteristics.

The claims data in our data set contained patient-level information about the course of disease during each patient's hospital stay, as well as the dates of hospital admission and discharge, the type of hospital unit and ICD (International Statistical Classification of Diseases and Related Health Problems) codes. The quality reports contained general information at the hospital unit level, such as the number of patient cases treated and staffing numbers that relate to the situation at the end of 2017.

\section{Nurse staffing}

We obtained the nurse staffing level in each hospital unit by calculating a patient-to-nurse ratio (PTN) in line with the definition for measuring nursing workload as suggested by the National Office of Statistics in Germany. ${ }^{44}$ The PTN indicates how many patients a nurse has to care for during an average shift and is given by:

$$
\begin{gathered}
P T N=\frac{\text { occupation days } * 24 \text { hours }}{\text { nurses } * 220 \text { days } * 8 \text { hours }} \text { with } \\
\text { occupation days }=\text { inpatient } * \text { average length of stay. }
\end{gathered}
$$

The total number of nurses (based on full-time nurses employed) comprise all registered nurses with at least 3 years of training and assistant nurses with at least 1 year of training. The numbers are derived from the annual quality reports of each hospital, representing the situation at the end of the year and not accounting for sickness absences or other sources of within-year variations such as variation caused by holidays. To calculate occupation days, we used the number of inpatients and approximated the average length of stay or each hospital unit based on the average length of stay of more than 6.2 million inpatient cases available in our claims data set over the period 2014 to 2019. We draw on the 5-year period for this approximation because we cannot observe all patients in each hospital unit in 1 year; to ensure robustness, we considered only those hospital units with more than 150 observations to approximate the length of stay.

In addition to staffing levels, we accounted for the skill mix in each hospital unit by calculating the ratio of assistant nurses to the total number of nurses (measured in full-time equivalents):

$$
\text { skill mix }=\frac{\text { assistant nurses }}{\text { nurses }} .
$$

We excluded extreme values, that is, PTNs below 1 and above 20 , as well as skill-mix ratios above $25 \%$.

\section{Quality of nursing care}

Because the definition of nursing care varies from country to country, it is necessary to use an instrument that takes country-specific regulations into account. We therefore chose the Patients' Experience of Nursing Quality in Acute Hospitals (PENQuAH) instrument developed by Blume to analyse the relationship between nurse staffing and patient outcomes. ${ }^{43}$ The instrument was designed to evaluate patients' perceptions of quality of nursing care in German hospitals. The instrument consists of 24 items, which were chosen based on a review of the literature and interviews with nursing experts. To examine the scale's dimensionality and factor-based validity, Blume conducted exploratory and confirmatory factor analyses with a randomly split sample. ${ }^{43}$ Their exploratory factor analysis revealed that three main dimensions captured the structure of the underlying item set: general nursing care, guidance provided by nurses, and nurse-related patient loyalty to the hospital. The results of their confirmatory factor analysis suggested a good overall model fit $(\mathrm{CFI}=0.978$; $\mathrm{TLI}=0.976)$. Table 1 shows the three dimensions and exemplary related items.

We calculated each dimension of quality of nursing care by taking the arithmetic mean of the underlying items after recoding reverse-coded items. Dimensions 1 and 2 are on a scale of 1 to 5 , with 5 representing the best quality of nursing care, and dimension 3 is on a scale of $1-4$, with 4 representing the best quality of nursing care. Dimension one represents patients' perception of the general quality of nursing care. Dimension 2 represents patients' perception of the guidance provided by nurses. Dimension 3 comprises two items that capture patients' loyalty to a hospital based on the nursing care provided.

\section{Statistical model}

The results of previous studies suggest that the relationship between nurse staffing and patient outcomes varies across different types of hospital units. ${ }^{855} 42$ To account more accurately for potential differences across the 24 unit types in our sample and to depict potential heteroscedastic structures in the error term of the regression, we applied a fixed effects model. The model is given by:

$$
\begin{aligned}
Q_{o N C}(x) & =\alpha_{0}+\alpha_{10} P \tilde{T N}_{i u}+\alpha_{11} P \tilde{P T N}_{i u}^{2}+\alpha_{2} \tilde{s k i l l}_{i u} \\
& +\beta_{1} P T N_{u}+\beta_{2} \text { skill }_{u}+\gamma C_{i u}+\left(v_{0 u}+\varepsilon_{i u}\right)
\end{aligned}
$$

where $Q o N C_{i u}^{(x)}$ is the value of one of the three factors $x \in\{1,2,3\}$ for patient $i$ admitted to unit type $u, u \in\{1, \ldots, 24\} . \alpha_{0}$ is the intercept of the regression. $\tilde{P T N}_{i u}=\left(P T N_{i u}-P \bar{T} N_{u}\right)$ and $\tilde{s k i l l}_{i u}=\left(\right.$ skill $\left._{i u}-\overline{s k i l l}_{u}\right)$ with coefficients $\alpha_{10}$ and $\alpha_{0}$ are the mean-centred 
Table 1 Overview on dimensions of Patients' Experience of Nursing Quality in Acute Hospitals instrument

\begin{tabular}{llll}
\hline Dimension & \# Items & Exemplary items & Scale \\
\hline (1) $\quad$ General nursing care & 13 & $\begin{array}{c}\text { From my perspective, I always received the necessary } \\
\text { care in the hospital. } \\
\text { Nursing staff treated me respectfully and courteously. }\end{array}$ \\
(2) $\begin{array}{l}\text { Guidance provided by } \\
\text { nurses }\end{array}$ & $\begin{array}{c}\text { Nursing staff told or showed me how I may and should }-5 \text { (best) } \\
\text { move. } \\
\text { Nursing staff told or showed me how to use my medical } \\
\text { aids. }\end{array}$ \\
(3) Nurse-related loyalty & $\begin{array}{c}\text { Thinking about the nursing staff, would you select the } \\
\text { hospital again? } \\
\text { Thinking about the nursing staff, would you recommend } \\
\text { the hospital to your friends and family? }\end{array}$
\end{tabular}

independent nurse staffing variables of interest, which correspond to the patient-to-nurse and skill mix ratio of the hospital unit associated with patient $i$ minus the group means $\operatorname{PTN}_{u}$ and $\overline{s k i l l}_{u}$ for each unit type $u$. Assuming that the marginal effect of the PTN on quality of nursing care decreases as staffing levels increase, we also included a squared patient-to-nurse term with coefficient $\alpha_{11} \cdot \beta_{1}$ and $\beta_{2}$ are the coefficients of the between-unit effects. $C_{i u}$ represents a vector of patient-unit-related, hospital-unitrelated, and hospital-unit-related control variables at level one of the model. First, it includes the patient-to-physician (PTP) ratio, because it might correlate with the PTN ratio and also affect the outcome. ${ }^{27}$ Second, we account for in patient risks by including age, gender, and each patient's case severity reflected by the Patient Clinical Complexity Level (PCCL) index (0-6), which indicates the degree of comorbidities and complications for each patient. It is derived from a closed list of comorbidities and complications and is meant to predict a patient's need for hospital resources, such as nursing care. ${ }^{45}$ We directly incorporate the PCCL index in our model because sensitivity analyses using dummy variables for each score suggested a linear relationship. Furthermore, we control for the rurality of each patient's place of residence using an index ranging from one (urban area) to four (rural area), four hospital size categories (50-299, 300-499, 500—749 and at least 750 ), and monthly fixed effects. $v_{0 u}$ refers to the fixed effects for the 24 hospital unit types.

As most previous studies used dichotomised outcome variables, we transformed our three quality of nursing care measures into dichotomous outcome variables and estimated a generalised version of our fixed effects model using a logit link function for comparability purposes, that is, a logit model. To check the robustness of our main model, we estimated a random effects model. Lastly, replaced the PCCL index with the Elixhauser comorbidity categories. $^{46}$

Moreover, we conducted subgroup analyses. As suggested by previous studies, the association between nurse staffing and patient outcomes can differ depending on patients' case severity. ${ }^{8}{ }^{40}$ To study these potential differences, we split our sample into patients with low case severity $(\mathrm{PCCL}=0)$ and those with high case severity ( PCCL >0) and estimated our main regression model for each of the subsamples. Additionally, we considered that our results might vary due to differences in hospital size. ${ }^{641}$ We therefore split our sample into two categories-that is, patients admitted to hospitals with fewer than 500 beds (category 'small') and patients admitted to hospitals with at least 500 beds (category 'large'). Lastly, by categorising our unit types as medical or surgical, we estimated our statistical model separately for medical and surgical patients.

\section{Patient and public involvement}

This study is part of a larger project on the association between nurse staffing and quality of care. ${ }^{3} 4243$ The public, that is, a statutory health insurance, hospital managers and patient representatives were involved in the design of the overall project. In addition, patients, practitioners (nurses, physiotherapists, doctors) and scientific experts were involved in the development of the survey (described in more detail in Refs. 3 43). Results of the study and the overall project will be disseminated to the participants via the statutory health insurance and via additional practice-oriented publications and newsletters.

\section{RESULTS \\ Descriptive results}

After excluding extreme values for our nurse staffing variables and removing observations with missing values for one or more of the control variables, our final sample comprised 28136 patients ranging from 18 to 97 years of age (average: 61.12 years) who had been discharged from 3458 distinct hospital units in 1017 hospitals. $39.2 \%$ of the survey participants were female. table 2 illustrates the distribution of patients and the average response for each of the three dimensions of quality of nursing care across the 24 types of hospital units. Overall, the variation in the distribution of patients across the 24 unit types was large. Almost $50 \%$ of the patients had been discharged from general surgery or internal medicine, followed by orthopaedics, urology, neurology, trauma surgery and 
Table 2 Quality of nursing care across unit types

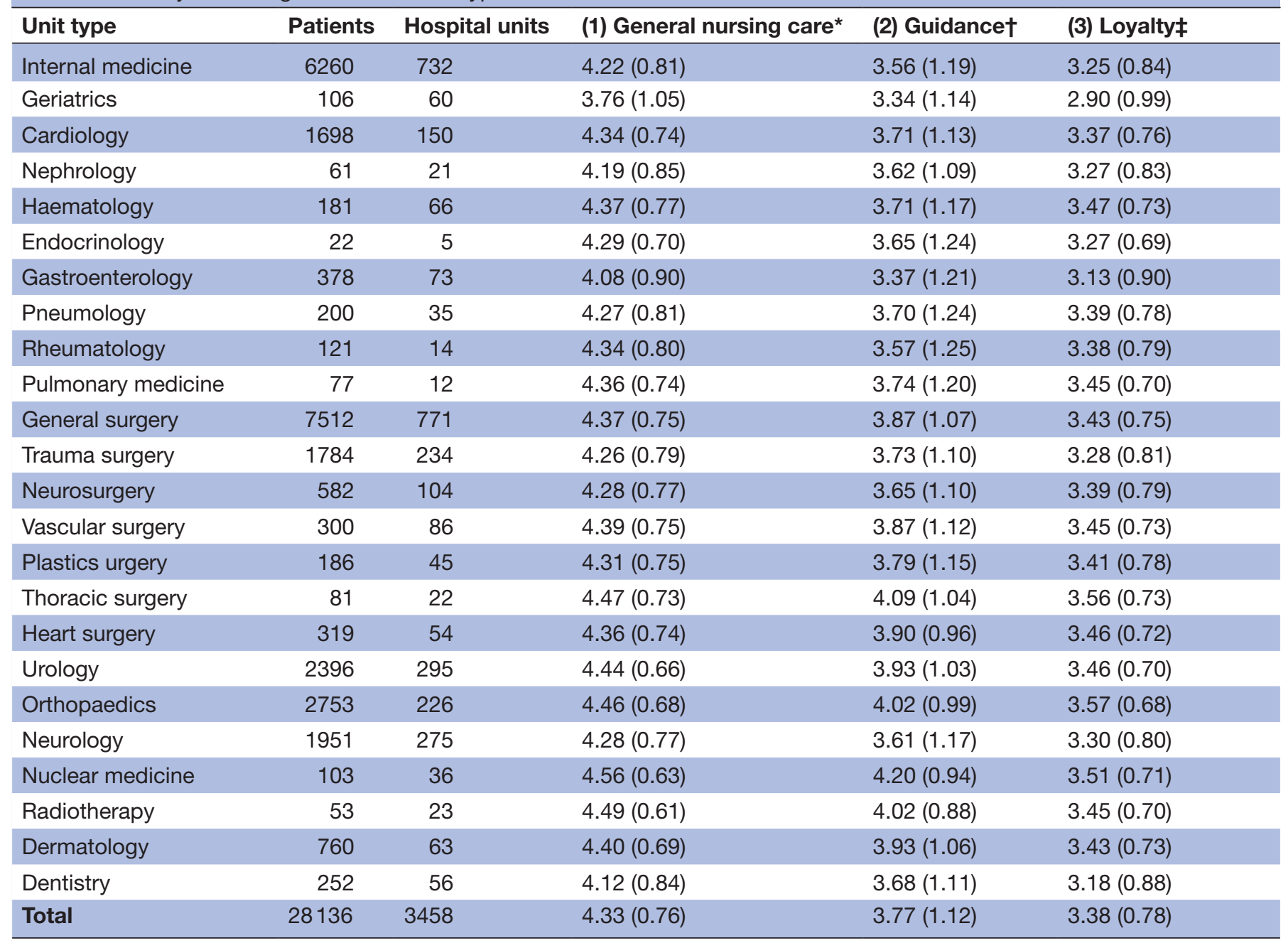

*Mean response for general nursing care, measured on a scale of 1-5, with 5 representing the best care. Standard deviation in parantheses. †Mean response for guidance provided by nurses, measured on a measured on a scale of 1-5, with 5 representing the best guidance. Standard deviation in parantheses.

¥Mean response for patient loyalty to the hospital, measured on a scale of $1-4$, with 4 representing the highest loyalty. Standard deviation in parantheses.

cardiology, from each of which between $6 \%$ and $10 \%$ of the patients had been discharged. All of the other unit types each accounted for less than $3 \%$ of the patients in our sample. In terms of our dependent variable, quality of nursing care, we obtained an average response of 4.33, 3.77 and 3.38 for the three dimensions general nursing care, guidance provided by nurses, and nurse-related patient loyalty to the hospital, respectively, indicating that the perceived quality of nursing care was above the scale average for each. In addition, we found that patient perception of the guidance provided by nurses was, on average, 0.56 scale points lower compared with the general perception of quality of nursing care. We also found that the average responses varied across hospital unit types. For instance, for dimensions 1 and 2, the average responses for patients discharged from internal medicine were 0.24 and 0.46 scale points lower, respectively, compared with orthopaedic patients.
For the patient-to-nurse and skill-mix-ratios, we obtained average values of 5.84 patients per nurse and $6.61 \%$, respectively. The PTN ranged from 3.77 patients a nurse has to care for in heart surgery to 9.75 in rheumatology. The skill-mix ratio ranged from $3.33 \%$ assistant nurses in nuclear medicine to $13.59 \%$ assistant nurses in endocrinology (see online supplemental appendix 1).

\section{Regression results}

As shown in table 3, our results indicate that the two nurse staffing variables were significantly related to quality of nursing care. An increase in the PTN significantly decreased the general quality of nursing care, the patient perception of nursing guidance, and nurserelated patient loyalty to a given hospital. Additionally, there were significantly positive associations between the squared PTN, on the one hand, and the general quality of nursing care, guidance and patient loyalty, on the other. 


\begin{tabular}{|c|c|c|c|}
\hline Effect ${ }^{*}$ & (1) General nursing care & (2) Guidance & (3) Loyalty \\
\hline$P \widetilde{T N}$ & $\begin{array}{l}-0.020(0.002) \\
(-0.033 ;-0.008)\end{array}$ & $\begin{array}{l}-0.023(0.018) \\
(-0.041 ;-0.004)\end{array}$ & $\begin{array}{l}-0.025(<0.001) \\
(-0.038 ;-0.012)\end{array}$ \\
\hline$\underset{P_{T N}^{2}}{\sim}$ & $\begin{array}{l}0.001(0.003) \\
(0.000 ; 0.002)\end{array}$ & $\begin{array}{l}0.001(0.030) \\
(0.000 ; 0.002)\end{array}$ & $\begin{array}{l}0.001(0.002) \\
(0.000 ; 0.002)\end{array}$ \\
\hline skill & $\begin{array}{l}-0.003(<0.001) \\
(-0.004 ;-0.001)\end{array}$ & $\begin{array}{l}-0.005(<0.001) \\
(-0.007 ;-0.003)\end{array}$ & $\begin{array}{l}-0.003(<0.001) \\
(-0.005 ;-0.002)\end{array}$ \\
\hline PCCL & $\begin{array}{l}-0.048(<0.001) \\
(-0.057 ;-0.040)\end{array}$ & $\begin{array}{l}-0.034(<0.001) \\
(-0.047 ;-0.022)\end{array}$ & $\begin{array}{l}-0.028(<0.001) \\
(-0.037 ;-0.019)\end{array}$ \\
\hline age & $\begin{array}{l}0.021(<0.001) \\
(0.018 ; 0.025)\end{array}$ & $\begin{array}{l}0.018(<0.001) \\
(0.013 ; 0.023)\end{array}$ & $\begin{array}{l}0.018(<0.001) \\
(0.014 ; 0.021)\end{array}$ \\
\hline$a g e^{2}$ & $\begin{array}{l}0.000(<0.001) \\
(0.000 ; 0.000)\end{array}$ & $\begin{array}{l}0.000(<0.001) \\
(0.000 ; 0.000)\end{array}$ & $\begin{array}{l}0.000(<0.001) \\
(0.000 ; 0.000)\end{array}$ \\
\hline $\begin{array}{l}\text { gender } \\
(=1 \text { if female })\end{array}$ & $\begin{array}{l}-0.192(<0.001) \\
(-0.210 ;-0.173)\end{array}$ & $\begin{array}{l}-0.276(<0.001) \\
(-0.303 ;-0.249)\end{array}$ & $\begin{array}{l}-0.140(<0.001) \\
(-0.159 ;-0.121)\end{array}$ \\
\hline rurality & $\begin{array}{l}0.014(0.004) \\
(0.004 ; 0.024)\end{array}$ & $\begin{array}{l}0.028(<0.001) \\
(0.014 ; 0.042)\end{array}$ & $\begin{array}{l}0.004(0.382) \\
(-0.005 ; 0.014)\end{array}$ \\
\hline PTP & $\begin{array}{l}-0.002(0.030) \\
(-0.003 ; 0.000)\end{array}$ & $\begin{array}{l}-0.002(0.026) \\
(-0.005 ; 0.000)\end{array}$ & $\begin{array}{l}-0.002(0.013) \\
(-0.003 ; 0.000)\end{array}$ \\
\hline $\operatorname{adj.} R^{2}$ & 0.061 & 0.055 & 0.045 \\
\hline observations & 28136 & 28136 & 28136 \\
\hline
\end{tabular}

$P$ values in square brackets, $95 \%$ Cls in parentheses.

PTN: mean-centred patient-to-nurse ratio; skill : mean-centred skill-mix ratio; PCCL: Patient Clinical Complexity Level index; PTP : meancentred patient-to-physician ratio.

${ }^{*}$ Fixed effects for the 24 unit types, months, and bed categories and between-unit effects for patient-to-nurse and skill mix included but not shown.

Hence, the negative effect of the PTN is greater when the PTN is smaller (in other words, if a nurse already has to care for a lot of patients, one additional patient has a less strong effect on quality perceptions). We illustrate the non-linear relationship in online supplemental appendix 2 (for factor 1$)$.

With regard to the skill-mix ratio, we found that an increase in the ratio of assistant nurses to the total number of nurses led to a significant decrease in general quality of nursing care, patient perception of nursing guidance, and patient loyalty. An increase in the PTP ratio of one additional patient a physician must care for significantly decreased the quality of nursing care dimensions.

The adjusted $R^{2}$ measure indicated that our model reduces the error in predicting an individual outcome for our three dimensions of quality of nursing care by between $4.5 \%$ and $6.1 \%$.

The regression results of the logit model indicated that an additional patient per nurse decreases the odds of a patient reporting high quality of nursing care. For nurse-related patient loyalty, this effect is significantly non-linear in the same way as in our main model (stated above). Increasing the share of assistant nurses decreases the odds of reporting high quality. An additional patient per physician does not significantly decrease the odds of reporting a high quality of quality of nursing care (see online supplemental appendix 3).

When we estimated a random effects model (online supplemental appendix 4) and when we replaced the PCCL index with the Elixhauser risk adjustment, our results remained robust.

\section{Sub group analyses}

Differentiating between patients according to their case severity, we found that the mean-centred PTN and its square are significantly associated with all three dimensions of patient-perceived quality of nursing care for patients with low case severity, but not for those with high case severity. The effects of the skill-mix ratio are also only significant for patients with low case severity, while the effects of the PTP ratio are slightly larger and only significant for high-case severity patients (except for general nursing care) (see online supplemental appendix 5).

When splitting our sample into patients admitted to a hospital with fewer than 500 beds and those admitted to a hospital with at least 500 beds, we found that an increase in the PTN significantly decreased general nursing care and nurse-related patient loyalty only for patients 
admitted to hospitals with fewer than 500 beds. Skill mix significantly affected general nursing care perceptions and nurse-related patient loyalty in small hospitals only, while it significantly affected the perception of guidance provided by nurses in small and in large hospitals. Moreover, we found a significant association between physician staffing and patient-perceived quality of nursing care for patients admitted to larger hospitals but not for patients admitted to smaller ones (see online supplemental appendix 6).

Finally, when we divided patients into those admitted to medical or surgical units, we found that the PTN significantly affected perceptions of guidance by nurses and nurse-related patient loyalty for medical patients only. The associations between the skill mix ratio and quality of nursing care seem largely unaffected by the sample split. Finally, it shows that medical patients were more sensitive to physician staffing compared with surgical patients (see online supplemental appendix 7).

\section{DISCUSSION}

Our results provide important new insights into the relationship between nurse staffing and patient outcomes, in particular, patient-perceived quality of nursing care. We found that patient-perceived quality of nursing care significantly decreased as staffing levels, measured using the PTN, decreased. This finding is in line with previous research that has examined the relationship between nurse staffing levels and general perceived quality of care measures. ${ }^{15} 16$ 19-22 $252647-49$ Our study adds to the previously ambiguous evidence in literature by providing insights into the specific aspects of perceived quality of nursing care that are affected by staffing levels. Evidence on the perceived quality of guidance provided by nurses has been inconsistent and scarce. ${ }^{2022}$ Our results, however, corroborate and extend the findings of Zhu et al, ${ }^{22}$ who found that higher staffing levels improved satisfaction with nurses' guidance on medications and medical aids, pain management, and self-help. ${ }^{22}$ With respect to nurserelated patient loyalty, our results confirm the findings of previous studies that have found that higher nurse staffing levels in hospitals increase the likelihood of patients generally recommending a hospital to family and friends. ${ }^{20}{ }^{21}$ Thus, nurse-related patient loyalty seems to be highly related to overall recommendation behaviour. In sum, staffing levels affect whether an adequate amount of time is devoted to caring and providing instructions as well as nurses' responsiveness to patients' individual needs. Furthermore, nurse staffing levels have direct consequences for hospitals in terms of patient loyalty. Yet, those effects are not linear; instead, the negative effects become smaller with rising numbers of patients per nurse. This decreasing marginal effect of the PTN on quality of nursing care with increasing staffing levels is in line with prior research ${ }^{15}$ and seems reasonable: when the ratio is small, each additional patient will substantially affect the amount of time and the responsiveness of a nurse, thus probably substantially reducing missed care. ${ }^{11-13}$ In contrast, the effect will be lower when a nurse already needs to care for a high number of (potentially less complex) patients and each additional patient only has a low impact.

Our results suggest that the nurses' level of educational attainment, as measured using the skill-mix ratio, significantly influences patient-perceived quality of nursing care. This finding adds to the few available studies on the relationship between skill mix and patient-perceived quality of care. ${ }^{151819}$ We found strong evidence that a higher proportion of assistant nurses, which means a lower proportion of professionalisation among nursing staff, is negatively associated with all three dimensions of quality of nursing care. Nurses with lower levels of educational attainment may have less training in interacting with patients, might work less efficiently and hence have less time per patient, or both. In addition, it is conceivable that they are less experienced in providing instructions suited to a patient's particular needs-for example, with regard to medication, pain relief, or the use of medical aids. Any of these factors could lead to negative perceptions among patients of quality of nursing care and potentially also to an increased number of adverse events. ${ }^{81750}$

We found that one additional patient per physician significantly reduced all three dimensions of patientperceived quality of nursing care. This is in line with the findings of, for example, West et $a l^{51}{ }^{1}$ who found that both physician and nurse staffing impact intensive care unit patient mortality. However, we found that the effect sizes for physician staffing were less pronounced compared with those for nurse staffing levels, indicating that our instrument is more closely related to nurse staffing than to physician staffing. This result might indicate that patients are not fully capable of differentiating between different occupational groups when assessing quality of care in hospitals. Another explanation might be that physician staffing does in fact have an impact on quality of nursing care; if physicians have to care for a large number of patients, they might omit passing on information which nurses need to adequately care for a patient-for example, information on the patients' needs or patient-specific treatment instructions. Additionally, stressed physicians might cause a bad civility climate, which in turn negatively impacts nurses' civility towards patients. $^{5253}$

The significant association we observed between the PTN and patient-perceived quality of nursing care was driven mainly by low-severity patients. This stands in contrast to the study of West et $a l,{ }^{51}$ which found that reductions in mortality risks from having more intensive care unit nurses is larger for patients who are the most severely ill. This might indicate that the effect of nurse staffing differs across hospital units (in particular, intensive vs non-intensive care) and/or across outcomes (in that case, patient-perceived quality of care and mortality). Additionally, for low-severity patients, the share of assistant nurses affects their perceptions of quality of nursing 
care, while for high-severity patients, the PTP ratio affects their perceptions of quality of nursing care. Because highseverity patients are more dependent on various health professionals and their collaborative performance, the quality of cooperation and consistency within and across occupational groups might explain their perceptions of quality of nursing care rather than staffing levels and skill mix. ${ }^{53}$ Low-severity patients might be less relying on different professionals, so that the composition of the nurses, as expressed in their skill mix, is of greater relevance to them.

Similarly, splitting our sample using two separate bed categories reveals that an increase in the PTN decreases patient-perceived quality of nursing care among patients admitted to hospitals with fewer than 500 beds rather than for patients admitted to hospitals with at least 500 beds. Yet, the patient-perceived guidance is only significantly affected by staffing levels in large hospitals (significant non-linear effect). While skill mix significantly affects patient-perceived general nursing care and loyalty in smaller hospitals only, it significantly relates to guidance in both small and large hospitals. Thus, we see some variation in how our variables of interest relate to the different quality of nursing care dimensions. The PTP ratio in turn only significantly affects patient-perceived quality of nursing care in large hospitals for all three quality of nursing care dimensions. This might be explained by a higher proportion of high-severity patients admitted to larger and potentially more highly specialised hospitals. In addition, in larger hospitals, collaboration across different occupational groups might be of higher importance than in smaller hospitals.

The stronger statistical significance of the relationship between nurse and physician staffing levels and quality of nursing care for medical patients compared with surgical patients seems plausible, as well. For nurse staffing, the finding is in line with previous studies that have analysed the relationship between nurse staffing levels and patient outcomes based on administrative data and found stronger associations for medical patients. ${ }^{8}$ The difference in effects might be explained by surgical patients being healthier (ie, as a precondition for being eligible for surgery) and therefore being less dependent on nurses. For medical patients, the collaboration between professional groups might also be of higher relevance, which can explain the significant effects of physician staffing.

Although our study makes important contributions to understanding the relationship between nurse staffing and patient outcomes, it is not without important limitations, each of which offers avenues for further research. First, both of the nurse staffing variables used in our analysis (ie, patient-to-nurse and skill-mix ratios) represent annual averages and do not capture day-to-day variations in nurse staffing. Similarly, even though we were able to consider several variables which are likely related to nurse staffing and patient outcomes, we might have omitted variable bias from other hospital-unit-related characteristics, such as the availability and use of technology, the share of temporary or immigrant nurses, the team climate, or absences due to sickness. These variables were not available in our data sample but might be associated with nurses' workload and also have an effect on patient outcomes. ${ }^{27}{ }^{53}$ In addition, the model complexity and the limited sample size drove our choice to conduct subgroup instead of moderating analyses. Thus, although this study overcomes several endogeneity issues of previous studies it cannot claim to fully address them. While the large size of our sample may compensate for some of these issues, future studies may want to draw on or collect more finely grained data covering day-to-day variations in nurse staffing variables and should try to account for further hospital characteristics. In addition, administrative staffing measures have been shown to deviate from perceived staffing adequacy ${ }^{54}{ }^{55}$; therefore, accounting for the latter in relation with quality of nursing care is a valuable avenue for further research, too. Another limitation this study shares with previous research is its cross-sectional nature. As the causal order and the generalisability of our results cannot be verified, future studies would be valuable to investigate the relationships in other settings and over time. Finally, the PENQuAH instrument has only been tested in Germany and our sample shows slight variations from the German hospitalised population, which might affect the generalisability of our results. As it has been able to provide more fine-grained insights into the dimensions of patient-perceived quality of nursing care, we recommend applying, adapting, and validating it to further data samples, and adjusting it to the hospital environments of other countries.

Our results have important implications for hospital managers and health policy makers pursuing stronger patient orientation. By providing strong evidence that quality of nursing care is affected by nurse staffing, we show that nurse staffing decisions are critical for favourable patient care experiences. We find that in addition to staffing levels, nurses' skill mix is an important factor associated with quality of nursing care. Therefore, we recommend considering nurses' levels of educational attainment, qualifications and specialisations when designing policies, such as minimum staffing regulations, to improve nurse staffing in hospitals.

Contributors JS and VW have originally designed the study. KD and US have acquired and analysed the data. JS, KD, and VW have interpreted the data. KD and VW have drafted the article and JS and US have critically revised it. KD is the paper's guarantor. All authors undertake to give final approval of the version to be published and agree to be accountable for all aspects of the work. No further writing assistance other than basic copy-editing has been provided.

Funding This material is based uponon work supported by the Innovation Fund of the German Federal Joint Committee, P.0. Box 1206 06, Berlin, Germany (01VSF17038).

\section{Competing interests None declared.}

Patient consent for publication Not applicable.

Ethics approval A declaration of compliance with terms of use and ethical standards from the University of Hamburg's WiSo Laboratories was obtained on 15 January 2019 (no approval number provided). Information and consent of the survey participants were conducted in written form prior to survey participation. 
A copy of the written form of Informed Consent, Privacy and Confidentiality was handed out to the subjects. A further copy was provided for the archive of the WiSo Laboratories.

\section{Provenance and peer review Not commissioned; externally peer reviewed.}

Data availability statement Data are available upon reasonable request. The data are in large parts owned by a German statutory health insurer, the Techniker Krankenkasse. To fulfill the legal requirements to obtain the data, researchers must obtain permission for a specific research question from the German Federal (Social) Insurance Office. Additionally, researchers must conclude a contract with the statutory health insurer regarding data access.

Supplemental material This content has been supplied by the author(s). It has not been vetted by BMJ Publishing Group Limited (BMJ) and may not have been peer-reviewed. Any opinions or recommendations discussed are solely those of the author(s) and are not endorsed by BMJ. BMJ disclaims all liability and responsibility arising from any reliance placed on the content. Where the content includes any translated material, BMJ does not warrant the accuracy and reliability of the translations (including but not limited to local regulations, clinical guidelines, terminology, drug names and drug dosages), and is not responsible for any error and/or omissions arising from translation and adaptation or otherwise.

Open access This is an open access article distributed in accordance with the Creative Commons Attribution Non Commercial (CC BY-NC 4.0) license, which permits others to distribute, remix, adapt, build upon this work non-commercially, and license their derivative works on different terms, provided the original work is properly cited, appropriate credit is given, any changes made indicated, and the use is non-commercial. See: http://creativecommons.org/licenses/by-nc/4.0/.

\section{ORCID iD}

Vera Winter http://orcid.org/0000-0001-7087-2400

\section{REFERENCES}

1 Kane RL, Shamliyan TA, Mueller C, et al. The association of registered nurse staffing levels and patient outcomes. Med Care 2007;45:1195-204.

2 Driscoll A, Grant MJ, Carroll D, et al. The effect of nurse-to-patient ratios on nurse-sensitive patient outcomes in acute specialist units: a systematic review and meta-analysis. Eur J Cardiovasc Nurs 2018;17:6-22.

3 Blume KS, Dietermann K, Kirchner-Heklau U, et al. Staffing levels and nursing-sensitive patient outcomes: umbrella review and qualitative study. Health Serv Res 2021;56:1-23.

4 Cook A, Gaynor M, Stephens M, et al. The effect of a hospital nurse staffing mandate on patient health outcomes: evidence from California's minimum staffing regulation. J Health Econ 2012;31:340-8

5 Blegen MA, Goode CJ, Spetz J, et al. Nurse staffing effects on patient outcomes: safety-net and non-safety-net hospitals. Med Care 2011;49:406-14.

6 Aiken LH, Clarke SP, Sloane DM, et al. Hospital nurse staffing and patient mortality, nurse burnout, and job dissatisfaction. JAMA 2002;288:1987-93.

7 Needleman J, Buerhaus P, Pankratz VS, et al. Nurse staffing and inpatient hospital mortality. N Engl J Med 2011;364:1037-45.

8 Needleman J, Buerhaus P, Mattke S, et al. Nurse-staffing levels and the quality of care in hospitals. N Engl J Med 2002;346:1715-22.

9 Stalpers D, de Brouwer BJM, Kaljouw MJ, et al. Associations between characteristics of the nurse work environment and five nurse-sensitive patient outcomes in hospitals: a systematic review of literature. Int J Nurs Stud 2015;52:817-35.

10 Leary A, Cook R, Jones S, et al. Mining routinely collected acute data to reveal non-linear relationships between nurse staffing levels and outcomes. BMJ Open 2016;6:e011177.

11 Aiken LH, Sloane DM, Ball J, et al. Patient satisfaction with hospital care and nurses in England: an observational study. BMJ Open 2018;8:e019189.

12 Redfern OC, Griffiths P, Maruotti A, et al. The association between nurse staffing levels and the timeliness of vital signs monitoring: a retrospective observational study in the UK. BMJ Open 2019;9:e032157.

13 Kalisch BJ, Tschannen D, Lee KH. Missed nursing care, staffing, and patient falls. J Nurs Care Qual 2012;27:6-12.

14 Rittenhouse DR, Shortell SM, Fisher ES. Primary care and accountable care - two essential elements of delivery-system reform. New England Journal of Medicine 2009;361:2301-3.
15 Oppel E-M, Young GJ. Nurse staffing patterns and patient experience of care: an empirical analysis of U.S. hospitals. Health Serv Res 2018;53:1799-818.

16 Martsolf GR, Gibson TB, Benevent R, et al. An examination of hospital nurse staffing and patient experience with care: differences between cross-sectional and longitudinal estimates. Health Serv Res 2016;51:2221-41.

17 Aiken LH, Sloane D, Griffiths P, et al. Nursing skill mix in European hospitals: cross-sectional study of the association with mortality, patient ratings, and quality of care. BMJ Qual Saf 2017;26:559-68.

18 McGillis Hall L, Doran D, Baker GR, et al. Nurse staffing models as predictors of patient outcomes. Med Care 2003;41:1096-109.

19 Potter P, Barr N, McSweeney M, et al. Identifying nurse staffing and patient outcome relationships: a guide for change in care delivery. Nurs Econ 2003;21:158-66.

20 Kutney-Lee A, McHugh MD, Sloane DM, et al. Nursing: a key to patient satisfaction. Health Aff 2009;28:w669-77.

21 Aiken LH, Sermeus W, Van den Heede K, et al. Patient safety, satisfaction, and quality of hospital care: cross sectional surveys of nurses and patients in 12 countries in Europe and the United States. BMJ 2012;344:e1717

22 Zhu X-wen, You L-ming, Zheng J, et al. Nurse staffing levels make a difference on patient outcomes: a multisite study in Chinese hospitals. J Nurs Scholarsh 2012;44:266-73.

23 Papastavrou E, Efstathiou G, Charalambous A. Nurses' and patients perceptions of caring behaviours: quantitative systematic review of comparative studies. J Adv Nurs 2011;67:1191-205.

24 Ausserhofer D, Schubert M, Desmedt M, et al. The association of patient safety climate and nurse-related organizational factors with selected patient outcomes: a cross-sectional survey. Int J Nurs Stud 2013:50:240-52

25 Ball JE, Murrells T, Rafferty AM, et al. 'Care left undone' during nursing shifts: associations with workload and perceived quality of care. BMJ Qual Saf 2014;23:116-25.

26 Cho S-H, Mark BA, Knafl G, et al. Relationships between nurse staffing and patients' experiences, and the mediating effects of missed nursing care. J Nurs Scholarsh 2017;49:347-55.

27 Griffiths P, Ball J, Drennan J, et al. Nurse staffing and patient outcomes: strengths and limitations of the evidence to inform policy and practice. a review and discussion paper based on evidence reviewed for the National Institute for health and care excellence safe staffing Guideline development. Int J Nurs Stud 2016;63:213-25.

28 Cho S-H, Ketefian S, Barkauskas VH, et al. The effects of nurse staffing on adverse events, morbidity, mortality, and medical costs. Nurs Res 2003;52:71-9.

29 Kim C-G, Bae K-S. Relationship between nurse staffing level and adult nursing-sensitive outcomes in tertiary hospitals of Korea: retrospective observational study. Int J Nurs Stud 2018;80:155-64.

30 Weiss ME, Yakusheva O, Bobay KL. Quality and cost analysis of nurse staffing, discharge preparation, and postdischarge utilization. Health Serv Res 2011;46:1473-94.

31 Twigg D, Duffield C, Bremner A, et al. The impact of the nursing hours per patient day (NHPPD) staffing method on patient outcomes: a retrospective analysis of patient and staffing data. Int J Nurs Stud 2011;48:540-8

32 Yakusheva O, Lindrooth R, Weiss M. Economic evaluation of the $80 \%$ baccalaureate nurse workforce recommendation: a patient-leve analysis. Med Care 2014;52:864-9.

33 Keers RN, Williams SD, Cooke J, et al. Understanding the causes of intravenous medication administration errors in hospitals: a qualitative critical incident study. BMJ Open 2015;5:e005948.

34 Lake ET, Shang J, Klaus S, et al. Patient falls: association with hospital magnet status and nursing unit staffing. Res Nurs Health 2010;33:413-25.

35 Dunton N, Gajewski B, Taunton RL, et al. Nurse staffing and patient falls on acute care hospital units. Nurs Outlook 2004;52:53-9.

36 Duffield C, Diers D, O'Brien-Pallas L, et al. Nursing staffing, nursing workload, the work environment and patient outcomes. Appl Nurs Res 2011;24:244-55

37 Van den Heede K, Lesaffre E, Diya L, et al. The relationship between inpatient cardiac surgery mortality and nurse numbers and educational level: analysis of administrative data. Int J Nurs Stud 2009b;46:796-803.

38 Sales A, Sharp N, Li Y-F, et al. The association between nursing factors and patient mortality in the eterans health administration: the view from the nursing unit level. Med Care 2008;46:938-45.

39 Brubakk K, Svendsen MV, Hofoss D, et al. Associations between work satisfaction, engagement and 7-day patient mortality: a crosssectional survey. BMJ Open 2019;9:e031704.

40 Diya L, Van den Heede K, Sermeus W, et al. The relationship between in-hospital mortality, readmission into the intensive care nursing 
unit and/or operating theatre and nurse staffing levels. $J$ Adv Nurs 2012;68:1073-81.

41 Rafferty AM, Clarke SP, Coles J, et al. Outcomes of variation in hospital nurse staffing in English hospitals: cross-sectional analysis of survey data and discharge records. Int J Nurs Stud 2007;44:175-82.

42 Dietermann K, Winter V, Schneider U, et al. The impact of nurse staffing levels on nursing-sensitive patient outcomes: a multilevel regression approach. Eur J Health Econ 2021;22:833-46.

43 Blume K, Kirchner-Heklau U, Winter V. Construction and validation of a scale to measure the quality of nurse delivered care in acute care settings, 2021.

44 National office of statistics. Gesundheit: grunddaten der krankenhäuser 2017 (basic data of hospitals of the year 2017. Wiesbaden: Statistisches Bundesamt, 2018.

$45 \mathrm{GmbH}$ I. G-DRG German diagnosis related groups: version 2019. definitionshandbuch. Siegburg, 2018.

46 Elixhauser A, Steiner C, Harris DR, et al. Comorbidity measures for use with administrative data. Med Care 1998;36:8-27.

47 Cho S-H, Yun S-C. Bed-to-nurse ratios, provision of basic nursing care, and in-hospital and 30-day mortality among acute stroke patients admitted to an intensive care unit: cross-sectional analysis of survey and administrative data. Int J Nurs Stud 2009;46:1092-101.

48 O'Brien-Pallas L, Li XM, Wang S, et al. Evaluation of a patient care delivery model: system outcomes in acute cardiac care. Can J Nurs Res 2010;42:98-120.
49 Sochalski J. Is more better?: the relationship between nurse staffing and the quality of nursing care in hospitals. Med Care 2004;42:1167-73.

50 Needleman J, Buerhaus PI, Stewart M, et al. Nurse staffing in hospitals: is there a business case for quality? Health Aff 2006;25:204-11.

51 West E, Barron DN, Harrison D, et al. Nurse staffing, medical staffing and mortality in intensive care: an observational study. Int $J$ Nurs Stud 2014;51:781-94.

52 Oppel E-M, Mohr DC. "Paying it forward": the link between providers' civility climate, civility toward patients and patient experience outcomes. Health Care Manage Rev 2020;45:141-50.

53 Van Bogaert P, Timmermans O, Weeks SM, et al. Nursing unit teams matter: impact of unit-level nurse practice environment, nurse work characteristics, and burnout on nurse reported job outcomes, and quality of care, and patient adverse events--a cross-sectional survey. Int J Nurs Stud 2014;51:1123-34.

54 Choi J, Staggs VS. Comparability of nurse staffing measures in examining the relationship between RN staffing and unit-acquired pressure ulcers: a unit-level descriptive, correlational study. Int $J$ Nurs Stud 2014;51:1344-52.

55 Winter V, Schreyögg J, Thiel A. Hospital staff shortages: environmental and organizational determinants and implications for patient satisfaction. Health Policy 2020;124:380-8. 